\title{
Coating carbon nanotubes with a polystyrene- based polymer protects against pulmonary toxicity
}

Lyes Tabet ${ }^{1}$, Cyrill Bussy ${ }^{1}$, Ari Setyan ${ }^{2,6}$, Angélique Simon-Deckers ${ }^{1}$, Michel J Rossi ${ }^{3}$, Jorge Boczkowski ${ }^{1,2,5 \dagger}$, Sophie Lanone $e^{1,3,4,5^{*}+}$

\begin{abstract}
Background: carbon nanotubes (CNT) can have adverse effects on health. Therefore, minimizing the risk associated with CNT exposure is of crucial importance. The aim of this work was to evaluate if coating multi-walled CNT (MWCNT) with polymers could modify their toxicity, thus representing a useful strategy to decrease adverse health effects of CNT. We used industrially-produced MWCNT uncoated (NT1) or coated (50/50 wt\%) with acidbased (NT2) or polystyrene-based (NT3) polymer, and exposed murine macrophages (RAW 264.7 cell line) or Balb/c mice by intratracheal administration. Biological experiments were performed both in vitro and in vivo, examining time- and dose-dependent effects of CNT, in terms of cytotoxicity, expression of genes and proteins related to oxidative stress, inflammation and tissue remodeling, cell and lung tissue morphology (optical and transmission electron microscopy), and bronchoalveolar lavage fluid content analysis.

Results: extensive physico-chemical characterization of MWCNT was performed, and showed, although similar dimensions for the 3 MWCNT, a much smaller specific surface area for NT2 and NT3 as compared to NT1 (54.1, 34 and $227.54 \mathrm{~m}^{2} / \mathrm{g}$ respectively), along with different surface characteristics. MWCNT-induced cytotoxicity, oxidative stress, and inflammation were increased by acid-based and decreased by polystyrene-based polymer coating both in vitro in murine macrophages and in vivo in lung of mice monitored for 6 months.
\end{abstract}

Conclusions: these results demonstrate that coating CNT with polymers, without affecting their intrinsic structure, may constitute a useful strategy for decreasing CNT toxicity, and may hold promise for improving occupational safety and that of general the user.

\section{Background}

Carbon nanotubes (CNT) exhibit unique properties, including mechanical, thermal and electrical conductivity, as well as field emission properties. These properties are associated with many applications (car industry, sport accessories, ...), and lead to a steady increase in the industrial production of CNT. However, it is increasingly obvious that exposure to nanoparticles in general, and CNT in particular, can have adverse effects on human health, especially at the level of the pulmonary system, which is a primary route of exposure [1].

\footnotetext{
* Correspondence: sophie.lanone@inserm.fr

+ Contributed equally

'INSERM U955, Créteil, F-94010 France, and Université Paris Est Val de Marne (UPEC), Créteil, F-94010, France

Full list of author information is available at the end of the article
}

This is raising considerable concern [2-9]. Therefore, minimizing the risk associated with CNT exposure is of crucial importance.

Among adverse health effects secondary to exposure to CNT, inflammation and oxidative stress are particularly worrisome because they can be associated with tissue remodeling and impaired function and/or carcinogenesis [10]. Recent data show that the length and rigidity of the nanotubes influences the pro-inflammatory effect of CNT [11]. However, the possible influence of other physicochemical properties remains incompletely understood [12]. Since surface characteristics influence the pro-inflammatory effect of spherical nanoparticles [13], we hypothesized that embedding CNT in polymers, thus modifying the surface environment of those CNT, could modify their toxicity, and thus represent a useful

\section{Biomed Central}


strategy to decrease adverse health effects of industrially-produced $\mathrm{CNT}$, without affecting their specific properties and further applications. The protective effect of the compatible solute Ectoine against carbon nanoparticle-induced lung inflammation has been nicely demonstrated recently [14]. However, a strategy based on the production of intrinsically safer nanomaterials seems to be much more promising. Such an approach is essential to the further development and safe use of $\mathrm{CNT}$, at an occupational level as well as at the level of the general user.

To assess our hypothesis, we utilized an original approach by coating industrially produced multi-walled CNT (MWCNT) with two different polymers (acidbased and polystyrene-based, respectively) that resulted in different surface environment but similar specific surface areas. To the best of our knowledge, although surface modifications is important to CNT toxicity [15-19], polymer coating has never been used before as an approach to modulate CNT toxicity. Coating could represent a useful tool, as it allows modifying CNT's external surface environment, without affecting their intrinsic structure. We investigated whether coating modified the toxicity of MWCNT in vitro in murine macrophages and in vivo in mice monitored for 6 months after intratracheal MWCNT instillation. Here, we report that MWCNT-induced cytotoxicity, oxidative stress, and inflammation in both models were increased by acid-based polymer coating and decreased by polystyrene polymer coating. These results demonstrate that surface characteristics play a major role in the biological response to $\mathrm{CNT}$ and that modifications of the surface environment by coating with specific compounds may constitute a useful strategy for decreasing CNT toxicity, without affecting their intrinsic structure, already at the time of their production. This may therefore hold promise for improving occupational safety as well as that of general users.

\section{Methods}

We investigated the effects of industrially-produced MWCNT that were either uncoated (NT1) or coated with carboxylic polyacid polymer (NT2) or a hydrophobic polystyrene polybutadiene polymethylmethacrylate polymer (NT3). These MWCNT were provided by ARKEMA-France (Colombes, France). The two coated MWCNT were composed of 50\% MWCNT and 50\% coating polymer by weight (determined by Thermo Gravimetric Analysis). Coatings were performed as follows; both coated MWCNT were produced by impregnation of NT1 powder (50\% weight) with a solution of polymer (carboxylic polyacid polymer for NT2, and polystyren polybutadiene polymethylmethacrylate for NT3), the solvent being thereafter eliminated by drying under vacuum conditions. Solvent was water for NT2, and methyl ethyl cetone for NT3. NT2 remained coated after dispersion in the culture medium, as revealed by the Toluidine Blue (TB) assay, which measures the stability of polymer grafting [20] (data not shown). Briefly, a $5.10^{-4} \mathrm{M}$ TB aqueous solution was prepared and $0.2 \mathrm{ml}$ of a buffer solution of 2-amino 2-methyl propanol was added to reach and maintain the solution $\mathrm{pH}$ value at 10. Each MWCNT sample was placed in TB solution at $30^{\circ} \mathrm{C}$ up to 24 hours. At different time points, uncomplexed TB molecules were removed by rapid washing (30 minutes) of the sample by a basic aqueous solution $\left(\mathrm{NaOH} 5.10^{-4} \mathrm{M}, \mathrm{pH} 9\right)$. Then, each sample was in $10 \mathrm{ml}$ of an aqueous acetic acid solution (50\% v/v) for 24 hours to obtain complete decomplexation of TB from the sample. The decomplexation solution was analyzed by UV/ visible spectroscopy at $633 \mathrm{~nm}$. There was no chemical link between the polymers and the nanotubes.

Both coated NT (NT2 and NT3) appear as powders, as the pristine one (NT1), and were dispersed in culture medium for both in vitro and in vivo experiments. The two polymers were also dispersed in culture medium in order to assess their intrinsic effects.

The effects of the three MWCNT were compared to those of crocidolite asbestos fibres (80 $\mathrm{nm}$ in diameter) kindly donated by Dr. Ghislaine Lacroix (INERIS, Verneuil-en-Hallatte-France) and of nanosized carbon black (CB, FR103, $95 \mathrm{~nm}$ in diameter; Degussa, Dusseldorf, Germany).

We chose to study industrially-produced MWCNT to obtain results relevant to occupational health, in the context of increasing industrial development and use of CNT.

\section{Physicochemical characterization of multi-walled carbon nanotubes}

MWCNT dimensions were measured using transmission electron microscopy (TEM), and MWCNT morphology was observed using scanning electronic microscopy (SEM). Chemical composition and carbon content were determined using inductively coupled plasma mass spectroscopy (ICP-MS), electron spectroscopy for chemical analysis (ESCA). Specific surface area was measured using Brunauer Emmett Teller (BET) adsorption isotherms of nitrogen at $77 \mathrm{~K}$. Surface functional groups were identified by surface titration using six probe gases flowing across a Knudsen flow reactor [21-23]. The relative uncertainty for both values (substrate/probe gas pair) is typically $25 \%$.

\section{Particle suspensions}

All particles were suspended at $10 \mathrm{mg} / \mathrm{ml}$ in Dulbecco's modified Eagle medium (DMEM). We choose not to disperse CNT using any particular agent because our 
aim was to examine the biological effects of surface properties of coated and uncoated CNT without any other interference. The suspensions were then vortexed for $1 \mathrm{~min}$, and sonicated (Elma S30H, 50-60 Hz) for 30 min under cooling conditions, with a 30-s interruption every 10 min with the vortex at maximum speed. Immediately after the end of sonication, the particle solutions were vortexed again for $1 \mathrm{~min}$ at maximum speed and diluted to various concentrations in culture medium (see below). CNT dispersion was quantified by dynamic light scattering using a Zetasizer Nano S (Malvern Instruments Ltd, Worcestershire, UK). Under control conditions, cells were cultured in serum-free DMEM without the particles (see below).

\section{In Vitro Studies}

\section{a. RAW 264.7 macrophage culture and exposure}

RAW 264.7 murine macrophages were purchased from the American Type Culture Collection (Manassas, VA), and were cultured as previously described [24]. Cells were exposed for 6 or 24 hours to 0.1 to $100 \mu \mathrm{g} / \mathrm{ml}$ $\left(0.02-20 \mu \mathrm{g} / \mathrm{cm}^{2}\right)$ of MWCNT or to $100 \mu \mathrm{g} / \mathrm{ml}(20 \mu \mathrm{g} /$ $\mathrm{cm}^{2}$ ) of crocidolite fibres or CB nanoparticles in serumfree medium, as it is known that serum can interact with nanomaterials and modify cellular response [25].

\section{b. Light microscopy}

Cell morphology was assessed by light microscopy after cell staining with Harris haematoxylin-phloxin. The size and number of the agglomerates present on the cells were determined as previously described [23]. Light microscopy studies were done in blinded fashion by two independent observers (LT and CB). The coefficient of variation for each measurement was $<5 \%$.

\section{c. Cell viability}

Cell viability was assessed using three methods, namely the MTT and Neutral Red assays and quantification of DNA content. These tests were performed as previously described [23]. Results were expressed as the mean of at least three independent experiments, each having six replicates, given as the ratio of the mean under each condition over the mean under the control condition (cells exposed to DMEM). Since nanomaterials may interfere with cytotoxicity tests [26], we performed the assays with and without $100 \mu \mathrm{g} / \mathrm{ml}$ of NT1, NT2, or NT3 during incubation with the dye, and we measured absorbance. No interference of NT1, NT2, or NT3 with any of the assays was observed (data not shown).

\section{d. Transmission Electron Microscopy}

Cells exposed for $24 \mathrm{~h}$ to $10 \mu \mathrm{g} / \mathrm{ml}$ of NT1, NT2, or NT3 were examined by TEM as previously described [23]. The percentage of cells with MWCNT-containing vacuoles after 24 hours' exposure to $100 \mu \mathrm{g} / \mathrm{ml}$ was determined on semi-fine slides. Under each stimulation condition, five fields were randomly selected from top to bottom across the vertical diameter of the sample. The measurements were made in blinded fashion by two independent observers (LT and CB). The coefficient of variation for the measurement was $<5 \%$.

\section{e. Reverse Transcription and Quantitative PCR (Q-PCR)}

The mRNA expression of various genes involved in oxidative stress and inflammation was measured using Q-PCR as described previously [23]. The primer sets are shown in Table 1 . The expression of the gene of interest was reported as the ratio over RpL13 expression.

\section{In Vivo Studies}

\section{a. Animal exposure}

The experiments were approved by the local Institutional Animal Care and Use Committee, and the experimental protocol complied with French legislation about animal studies. Male Balb/C mice aged 7-9 weeks and weighing $22 \pm 0.23 \mathrm{~g}$, were purchased from Janvier (Le Genest-St-Isle, France) and housed in standard wiretopped cages in temperature-controlled units with food and water ad libitum.

NT1, NT2, or NT3 were suspended in DMEM as for the in vitro studies. The suspension was instilled intratracheally after anaesthesia of the animal with $1.6 \mathrm{mg}$ ketamine (Merial, Lyon, France) plus $300 \mathrm{mg}$ xylazine (Bayer, Puteaux, France). A single dose (10 or $100 \mu \mathrm{g} /$ mouse) of

Table 1 Sequences of primers used for quantitative PCR assays

\begin{tabular}{|c|c|c|}
\hline Gene & Forward Primer & Reverse Primer \\
\hline$R P L-13$ & GTGGTCCCTGCTGCTCTCCAA & CGATAGTGCATCTTGGCCTITT \\
\hline HO-1 & CACGCATATACCCGCTACCT & CCAGAGTGTTCATTCGAGCA \\
\hline GPX-1 & TGAAGAGATTCTGAATTCCCTCAAG & CAGGAAGGTAAAGAGCGGGTG \\
\hline SOD-1 & CAAATTACAGGATTAACTGAAGGCC & GGCCACCATGTTTCTTAGAGTGAG \\
\hline SOD-2 & CTACGTGAACAATCTCAACGCC & ATTAATATGTCCCCCACCATTGAAC \\
\hline TNF- $\alpha$ & CTGTCTACTGAACTTCGGGGTGAT & GGTCTGGGCCATAGAACTGATG \\
\hline CXCL2 & GAACATCCAGAGCTTGAGTGTGAC & CTTGCCTTTGTTCAGTATCTITTGG \\
\hline$\alpha-2$ collagen-1 & GGCTATGACTITGGTTTTGAAGGA & CGTTGTCGTAGCAGGGTTCTTT \\
\hline$\alpha-1$ collagen-3 & CCAGAACATTACATACCACTGCAAA & GTGTTIAGTACAGCCATCCTCTAGAACTG \\
\hline
\end{tabular}

$R P L 13$, ribosomal protein L13; HO-1, heme oxygenase-1; SOD, superoxide dismutase; GPX-1, Glutathione peroxidase-1; $C X C L 2$, macrophage inflammatory protein-2; TNF- $\alpha$, tumour necrosis factor alpha. 
NT1, NT2, or NT3 was given to each animal. The highest dose was relevant to the $20 \mu \mathrm{g} / \mathrm{cm}^{2}$ concentration used in the in vitro studies [27]. The mice were sacrificed 1, 7, 30, 90 , or 180 days post-instillation. In a subset of experiments, animals were exposed to $200 \mu \mathrm{g}$ of NT2 or NT3, in order to allow adequate comparison with $100 \mu \mathrm{g}$ NT1.

\section{b. Bronchoalveolar Lavage (BAL) and Lung Recovery}

The mice were anesthetized with an intramuscular injection of ketamine/xylazine and sacrificed by exsanguination. BAL fluid analysis and lung tissue recovery were performed as described previously [28]. The percentage of macrophages with MWCNT-containing vacuoles was determined as for the in vitro studies. The mRNA expression of the genes evaluated in vitro was measured using Q-PCR on homogenates, with the same set of primers (Table 1). In addition, we measured the expression of collagen-1 and -3 , used as markers for interstitial fibrosis.

\section{c. Histological study of lung samples}

Lung histology was examined in a subset of animals different from that used for investigating BAL fluid and lung gene expression determination. The lungs were fixed with $0.8 \mathrm{ml}$ of a $1: 1 \mathrm{mix}$ of $0.9 \%$ saline with Tissue-Teck ornithine carbamoyltransferase fluid (Sakura, Zoetervoude, The Netherlands) and were snapfrozen in liquid nitrogen. Lung histology studies were performed as described previously [29].

The number and size of MWCNT agglomerates in the lungs of animals exposed for 24 hours, 1 month, or 6 months was measured in five representative animals per group. For each animal, five fields were randomly selected from top to bottom across the vertical diameter of the section. Calculations were performed using ImageJ software (http://rsbweb.nih.gov/ij/), and the analysis was performed in blinded fashion by two independent observers (LT and CB). The coefficient of variation for each measurement was $<5 \%$.

\section{Statistical Analysis}

The values from at least four different experiments (in vitro study) and 6-8 animals (in vivo study) are represented as box and whisker plots. In vitro experiments were performed in triplicate. The data were analysed using the non-parametric Kruskal-Wallis test, followed by Dunn's multiple comparison test where appropriate. For all tests, $p$ values smaller than 0.05 were considered significant.

\section{Results}

\section{Physicochemical characterization of multi-walled carbon} nanotubes

The NT1 used in this study have been extensively characterized [23]. NT2 and NT3, the two coated MWCNT were composed of 50\% MWCNT and 50\% coating polymer by weight. They were produced by chemical vapour deposition on a supported catalyst in a fluidized bed that yielded spheric heaps of MWCNT entangled around the supported catalyst, measuring about few hundred microns in diameter, and forming a freeflowing powder.

Typical SEM images of the various MWCNT are shown in Figure 1 and Additional file 1, figure S1. Physicochemical characterization (Table 2) showed that NT2 and NT3 had similar dimensions and metallic impurities compared to NT1. Specific surface area was similar for NT2 and NT3 and smaller than the specific surface area of NT1. Furthermore, all three MWCNT showed micrometric agglomerates in suspension (as demonstrated previously [23]), whose diameter was largest for NT1 and smallest for NT2. Surface chemical analysis of functional groups located on the surface of the MWCNT showed a larger amount of acidic sites on NT2 compared to the other two MWCNT (Table 3). Moreover both NT2 and NT3 contain a significant amount of surface carbonyl. No basic oxides are present, as seen by the ratio of the uptake of $\mathrm{HCl} / \mathrm{CF}_{3} \mathrm{COOH}$.

\section{In vitro studies}

We first evaluated the effects of the three MWCNT on macrophages (murine cell line RAW 264.7), which play a key role in host defence mechanisms against foreign bodies. Figure 2 shows representative light microscopy images of RAW macrophages exposed for $24 \mathrm{~h}$ to the three MWCNT, CB, and asbestos fibres. Even after
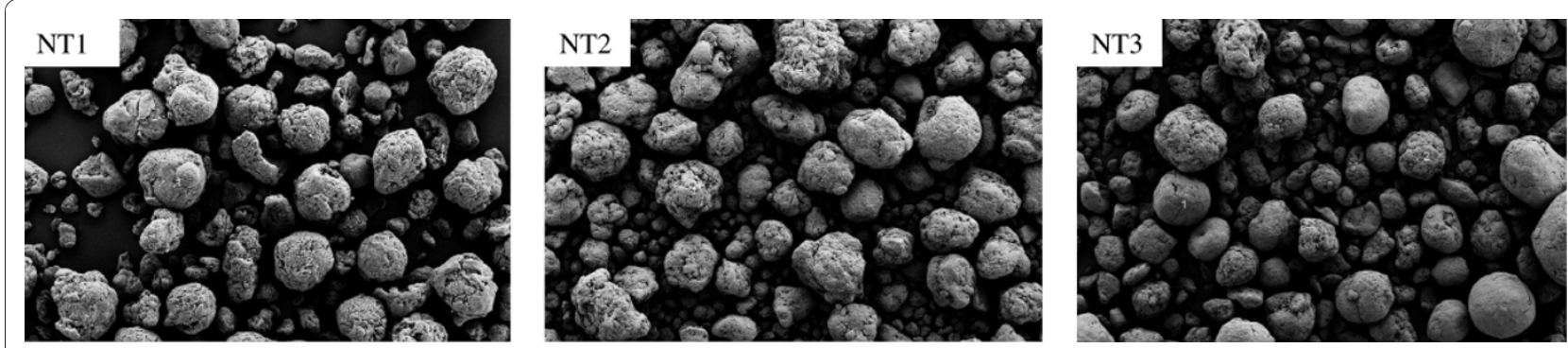

Figure 1 SEM observations. Representative scanning electron microscopy (SEM) image of uncoated multi-walled carbon nanotubes (NT1) and of the same nanotubes coated with carboxylic polyacid polymer (NT2) or polystyrene polybutadiene polymethacrylate polymer (NT3). 
Table 2 Physicochemical characteristics of the multi-walled carbon nanotubes (MWCNT) used in the study

\begin{tabular}{|c|c|c|c|c|}
\hline & & NT1 & NT2 & NT3 \\
\hline \multicolumn{2}{|l|}{ Coating polymer (50/50 wt\%) } & None & Carboxylic polyacid polymer & PMMA $^{a}$ polymer \\
\hline \multicolumn{2}{|l|}{ Diameter (nm) } & $12 \pm 1$ & $12 \pm 1$ & $12 \pm 1$ \\
\hline & $0-15 \mathrm{~nm}$ & $85 \%$ & $85 \%$ & $85 \%$ \\
\hline \multirow[t]{2}{*}{ Size distribution (diameter) } & $15-30 \mathrm{~nm}$ & $13 \%$ & $13 \%$ & $13 \%$ \\
\hline & $>30 \mathrm{~nm}$ & $2 \%$ & $2 \%$ & $2 \%$ \\
\hline \multicolumn{2}{|l|}{ Length $(\mu \mathrm{m})$} & $0.1-13$ & $0.1-13$ & $0.1-13$ \\
\hline \multirow[t]{2}{*}{ Metallic impurities } & Aluminium (\%) & 3.2 & 1.15 & 1.25 \\
\hline & Iron (\%) & 2.45 & 0.75 & 0.85 \\
\hline \multicolumn{2}{|l|}{ Specific surface $\left(\mathrm{m}^{2} / \mathrm{g}\right)$} & 227.4 & 54.1 & 34 \\
\hline \multicolumn{2}{|c|}{ Agglomerate size - mean diameter $(\%<10 \mu \mathrm{m})$} & $338(0.13)$ & $118(1.45)$ & $267(0.83)$ \\
\hline
\end{tabular}

${ }^{a}$ Polystyrene polybutadiene polymethylacrylate (PMMA).

thorough washing, MWCNT agglomerates were seen in contact with the cells. The number of these agglomerates was largest for NT2 and smallest for NT3 (Table 4). All three MWCNT were internalized by the macrophages within vacuoles, as single nanotubes or as agglomerates, without any modification of cell morphology (TEM images, Figure 3a and Additional file 2, figure S2). Quantitative analysis of internalization in vacuoles showed that the percentage of cells containing internalized nanotubes was greatest with NT2 and smallest with NT3 (Figure 3b). Few MWCNT were seen in the cytoplasm. Taken together, these results indicate stronger "attachment" to the cell surface and greater internalisation with NT2 than with NT1 or NT3, despite the similar dimensions, metallic impurities of the three MWCNT, and a specific surface similar to NT3.

Cell viability was assessed using several tests. The MTT assay showed a similar dose-dependent decrease in mitochondrial metabolism after $24 \mathrm{~h}$ of exposure to NT1, NT2, and crocidolite (Figure 4a). This effect was already detectable after $6 \mathrm{~h}$ with NT2 (Additional file 3, figure S3). No such effect was observed with NT3, CB, or the polymers alone (data not shown). The Neutral Red assay (which measures cell membrane permeability) and DNA content quantification (which measures cell number) showed no significant alterations in cells exposed to any of the MWCNT or other materials (data not shown). The preferential effect of nanoparticles on mitochondrial metabolism has been described previously [23,30-32].

We next quantified the expression of several genes involved in inflammation and oxidative stress. Expression of the mRNAs for the antioxidant gene HO-1 and the pro-inflammatory gene CXCL2 was significantly increased in cells exposed to crocidolite, NT1, or NT2, compared to control cells exposed to medium alone (Figures 4b and 4c). NT1 induced a significantly greater increase in CXCL2 expression than did NT2 $(p<0.05$, Figure 4c). No such modifications occurred after cell incubation with NT3, CB or the polymers alone (data not shown). Finally, with none of the nanomaterials studied were changes seen in mRNA expression of the antioxidant genes GPX-1, SOD-1, or $S O D-2$, or of the inflammatory gene TNF-a (data not shown).

Table 3 Characterization using a Knudsen flow reactor of the surface functional groups present on the multi-walled carbon nanotubes (MWCNT)

\begin{tabular}{|c|c|c|c|c|c|c|c|}
\hline MWCNT & $\begin{array}{c}\text { Gas } \\
\text { [gas-phase probe } \\
\text { molecules] }\end{array}$ & $\begin{array}{c}\mathrm{N}\left(\mathrm{CH}_{3}\right)_{3} \\
\text { [acidic sites] }\end{array}$ & $\begin{array}{c}\mathrm{HCl} \\
\text { [basic sites] }\end{array}$ & $\begin{array}{c}\mathrm{CF}_{3} \mathrm{COOH} \\
\text { [basic sites] }\end{array}$ & $\begin{array}{c}\mathrm{NH}_{2} \mathrm{OH} \\
\text { [carbonyl } \\
\text { functions] }\end{array}$ & $\begin{array}{c}\mathrm{O}_{3} \\
\text { [oxidisable } \\
\text { sites] }\end{array}$ & $\begin{array}{c}\mathrm{NO}_{2} \\
\text { [oxidisable } \\
\text { sites] }\end{array}$ \\
\hline \multirow[t]{2}{*}{ NT1 } & $\mathrm{N}^{\circ} / \mathrm{mg}^{a}$ & $3.0 \cdot 10^{15}$ & $8.1 \cdot 10^{16}$ & $2.4 \cdot 10^{16}$ & $2.4 \cdot 10^{17}$ & $3.9 \cdot 10^{18}$ & $1.2 \cdot 10^{16}$ \\
\hline & $\mathrm{N} / \mathrm{cm}^{2 b}$ & $1.32 \cdot 10^{12}$ & $35.6 \cdot 10^{12}$ & $10.6 \cdot 10^{12}$ & $105.5 \cdot 10^{12}$ & $1715 \cdot 10^{12}$ & $5.3 \cdot 10^{12}$ \\
\hline \multirow[t]{2}{*}{ NT2 } & $\mathrm{N} / \mathrm{mg}^{a}$ & $6.4 \cdot 10^{15}$ & $4.4 \cdot 10^{16}$ & $5.9 \cdot 10^{15}$ & $3.4 \cdot 10^{17}$ & $1.8 \cdot 10^{17}$ & $1.2 \cdot 10^{15}$ \\
\hline & $\mathrm{N} / \mathrm{cm}^{2 b}$ & $11.8 \cdot 10^{12}$ & $81.3 \cdot 10^{12}$ & $1.1 \cdot 10^{12}$ & $628.5 \cdot 10^{12}$ & $332.7 \cdot 10^{12}$ & $2.2 \cdot 10^{12}$ \\
\hline \multirow[t]{2}{*}{ NT3 } & $\mathrm{N} / \mathrm{mg}^{a}$ & $2.6 \cdot 10^{14}$ & $1.4 \cdot 10^{16}$ & $5.8 \cdot 10^{14}$ & $2.0 \cdot 10^{17}$ & $1.1 \cdot 10^{18}$ & $1.9 \cdot 10^{15}$ \\
\hline & $\mathrm{N}^{\circ} / \mathrm{cm}^{2 b}$ & $0.8 \cdot 10^{12}$ & $41.2 \cdot 10^{12}$ & $1.7 \cdot 10^{12}$ & $588 \cdot 10^{12}$ & $3235 \cdot 10^{12}$ & $5.6 \cdot 10^{12}$ \\
\hline
\end{tabular}

\footnotetext{
${ }^{a}$ Number of probe molecules taken up per $\mathrm{mg}$ of deposited nanoparticles.

${ }^{b}$ Number of probe molecules taken up per square $\mathrm{cm}$ of MWCNT $\left(\mathrm{no} / \mathrm{cm}^{2}\right)$, using the BET surface as a surface metric.

NT1, uncoated MWCNT; NT2, MWCNT coated with carboxylic polyacid polymer; NT3, MWCNT coated with polystyrene polybutadiene polymethylacrylate polymer.
} 

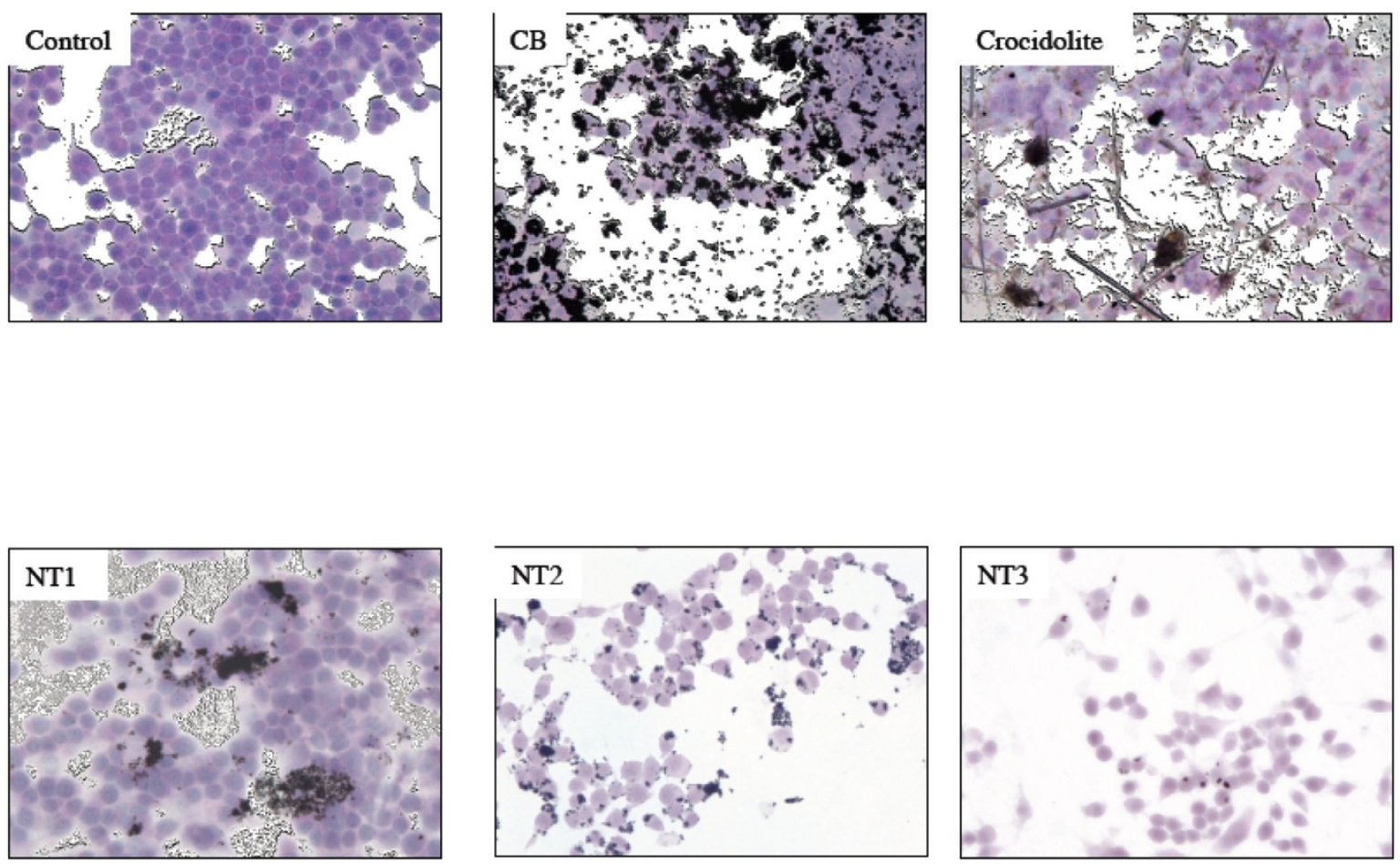

Figure 2 Effects of MWCNT on macrophages in vitro - light microscopy observations. Representative light microscopy images of RAW 264.7 cells exposed for $24 \mathrm{~h}$ to culture medium alone (Control) or $100 \mu \mathrm{g} / \mathrm{ml}$ of carbon black (CB), crocidolite fibres, NT1, NT2 or NT3. Original magnification: $\times 20$. Abbreviations are the same as in Figure 1.

\section{In vivo studies}

The relevance of the in vitro data was evaluated in vivo in Balb/c mice, each given a single intratracheal instillation of either $10 \mu \mathrm{g}$ or $100 \mu \mathrm{g}$ of MWCNT then monitored for up to 6 months. BAL fluid analysis showed that exposure to NT2 induced a dose-dependent increase in total cell count ( $p<0.05$ vs. control, Figure 5a) and a significant influx of neutrophils and macrophages ( $p<0.05$ vs. control, Figure $5 \mathrm{~b}$ and $5 \mathrm{c}$ ). These effects were observed $24 \mathrm{~h}$ post-instillation and

Table 4 Size and number of carbon nanotube agglomerates found in vitro 24 hours after exposure to multi-walled carbon nanotubes (MWCNT)

\begin{tabular}{ccc}
\hline MWCNT & Surface area $\left(\boldsymbol{\mu m}^{2}\right)$ & Number/field \\
\hline NT1 & $30.23 \pm 7.32$ & $18.5 \pm 1.5$ \\
\hline NT2 & $12.87 \pm 3.4^{*}$ & $37.3 \pm 3.7^{*}$ \\
\hline NT3 & $4.97 \pm 1.61^{\#}$ & $9.3 \pm 1.9^{\#}$ \\
\hline
\end{tabular}

*: $p<0.05$ vs. NT1.

$\#: \mathrm{p}<0.05$ vs. NT1 and NT2.

NT1, uncoated MWCNT; NT2, MWCNT coated with carboxylic polyacid polymer; NT3, MWCNT coated with polystyrene polybutadiene polymethylacrylate polymer. lasted up to 1 month. With NT1, the modifications were similar to those produced by NT2 but less marked and present only $24 \mathrm{~h}$ post-instillation. No significant effect was observed after administration of polymers alone (data not shown). All three MWCNT were internalized in macrophages between 1 day and 1 month after instillation (Additional file 4, figure S4). The percentage of macrophages with MWCNTcontaining vacuoles was higher with NT2 than with NT1 or NT3, and was also observed between 1 day and 1 month after instillation $(p<0.05$, Figure $5 \mathrm{~d})$. MWCNT internalization was independent from the MWCNT dose. The percentages of macrophages with MWCNT-containing vacuoles were not significantly different between NT1 and NT3.

Histological studies of the lungs $24 \mathrm{~h}$ after instillation showed the presence of widespread micrometric MWCNT agglomerates, which were mainly located in the bronchiolar lumen and alveolar ducts with NT1 and near the bronchioles and in the alveoli with NT2. NT3 agglomerates were scarce and confined to the alveoli (Figure $6 \mathrm{a}$ and 6b). Agglomerate size was greatest with NT1 and smallest with NT3, whereas agglomerate number was greatest with NT2 and smallest with NT3 (Figure 6c). After 1 week, 


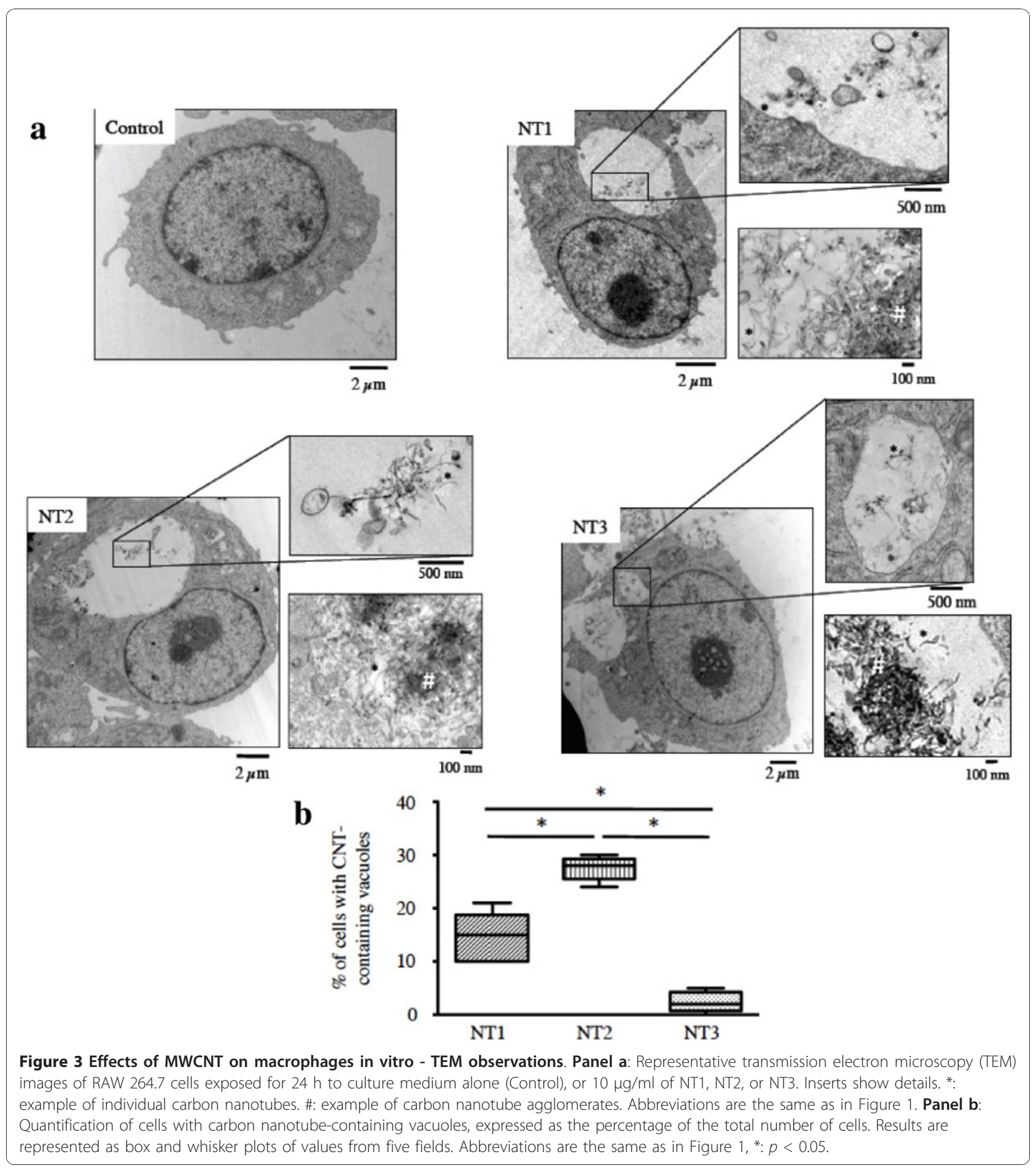

clusters of cells surrounding visible MWCNT agglomerates were seen in the lungs of animals exposed to NT1 or NT2. These clusters were mainly located near the terminal bronchioles but were also found in the alveolar ducts and alveoli. They were still present 6 months post-exposure (Additional file 5, 6, 7, 8, 9, and 10 figures S5, S6, S7, S8,
S9, and S10). No evidence of fibrosis was found with any of the three MWCNT.

The mRNA expression of various genes implicated in oxidative stress, inflammation, and fibrosis was quantified in lung homogenates, as for the in vitro experiments. Significant increases in lung mRNA expression 


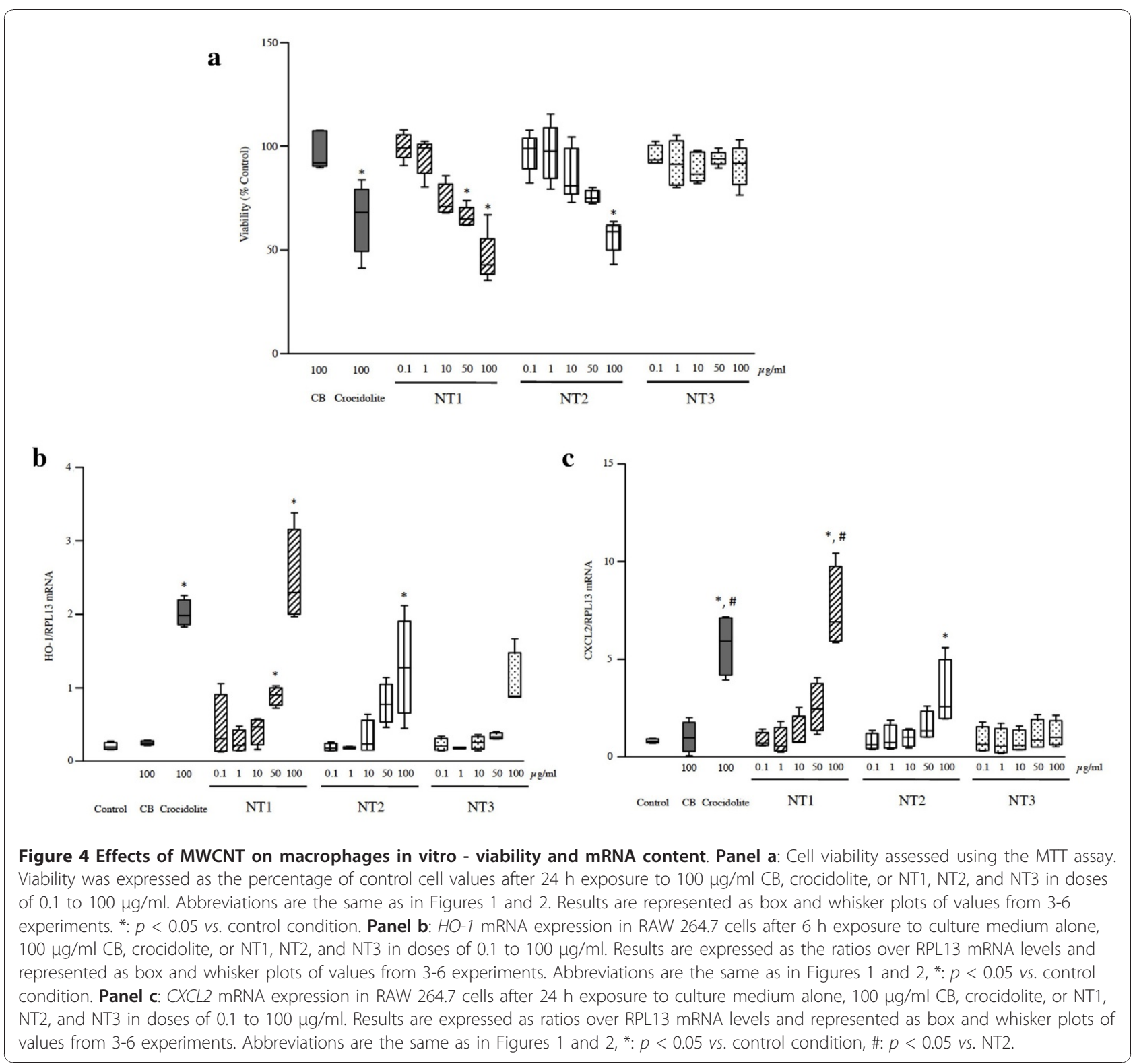

of SOD-2 and HO-1, TNF- $\alpha$ and CXCL2, and collagen-1 and -3 were observed between 1 day and 1 week postinstillation in animals exposed to NT2, compared to control animals $(p<0.05$ for all comparisons, Figure $7 d$ and data not shown). The expression of these genes returned to basal levels by 1 month post-instillation, except for HO-1 whose expression returned to basal levels only after 3 months (see Figure $7 \mathrm{e}$ for values at 6 months). No modifications in gene expression were seen in animals exposed to NT1, NT3 or polymers alone (data not shown). With none of the three MWCNT did changes occur in the expression of GPX1, SOD-1, or TGF-b mRNA (data not shown).

\section{Discussion}

Taken together, these results show that coating MWCNT with an acidic polymer reduced their specific surface five-fold but enhanced their dispersion in culture medium and their internalization by macrophages both in vitro and in vivo, compared to uncoated MWCNT. These results agree with earlier data [33] showing that the presence of acidic groups such as phenolic or carboxyl groups on the surface of carbon materials facilitates the internalization of these materials by mouse macrophages. The marked internalization of NT2 by mouse macrophages in our study was associated with the induction of a cytotoxic, 


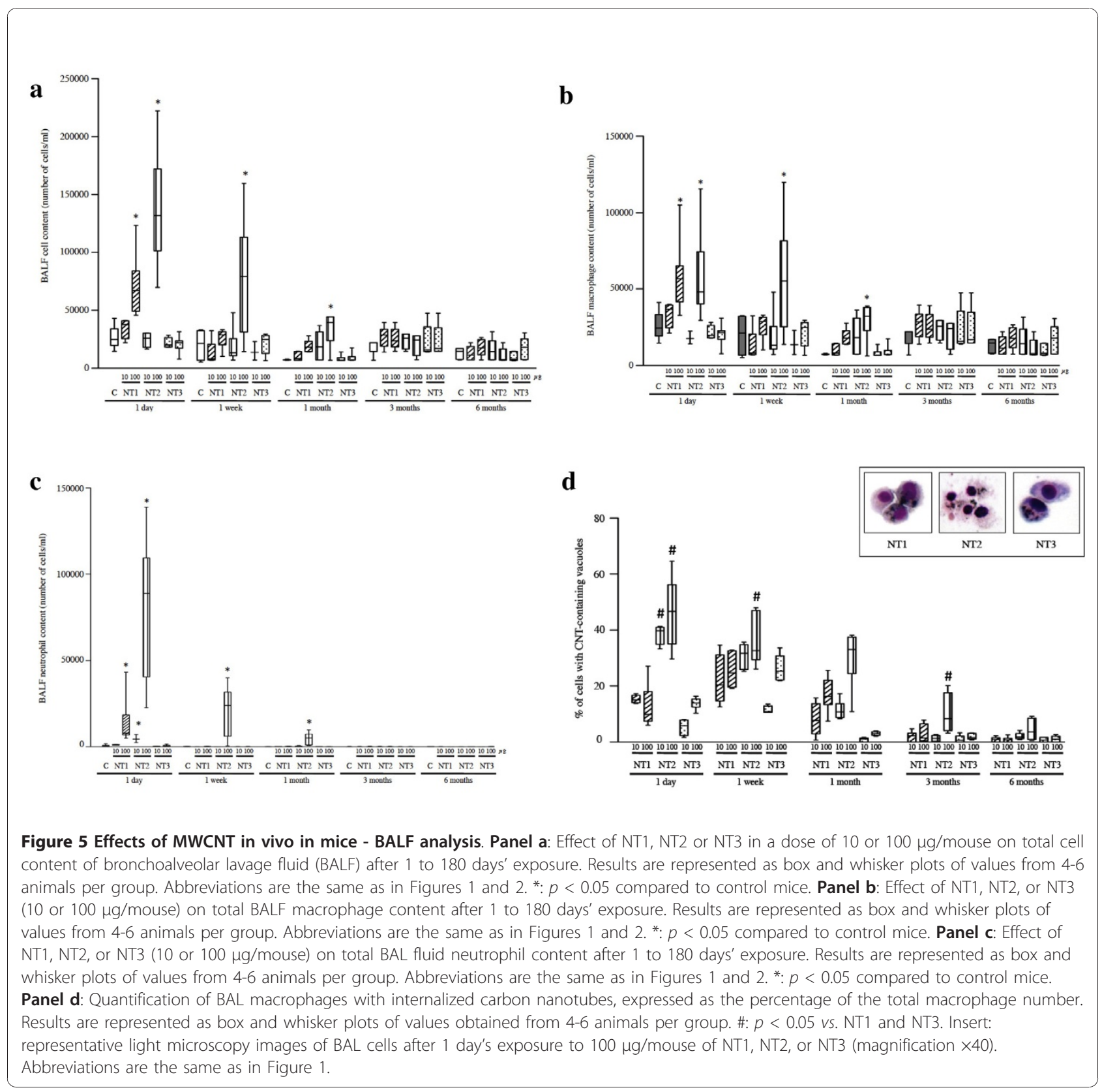

oxidative, and inflammatory response despite the marked decrease in specific surface, compared to NT1. A similar direct relationship between the degree of internalization and the severity of the inflammatory response was described with metallic nanoparticles [34]. In contrast to the in vitro experiments, in which the oxidative and inflammatory effects of NT1 and NT2 were similar, the in vivo experiments showed stronger oxidative and inflammatory responses to NT2 than to NT1, suggesting that cells other than macrophages were involved in the response to NT2 in vivo. This hypothesis is supported by the smaller size and larger number of NT2 agglomerates in the alveolar wall, suggesting enhanced contact of alveolar cells with NT2 compared to NT1. Accordingly, Shvedova and coworkers [35] demonstrated that exposure of mice to relatively well-dispersed single-walled CNT by inhalation produced a stronger inflammatory response than did pharyngeal aspiration of an agglomerated particle suspension (micrometer-size agglomerates). A stronger inflammatory response to NT2 could result from their acidic surface, in addition to their better internalization. Indeed, we recently obtained data showing that the inflammatory response of murine 


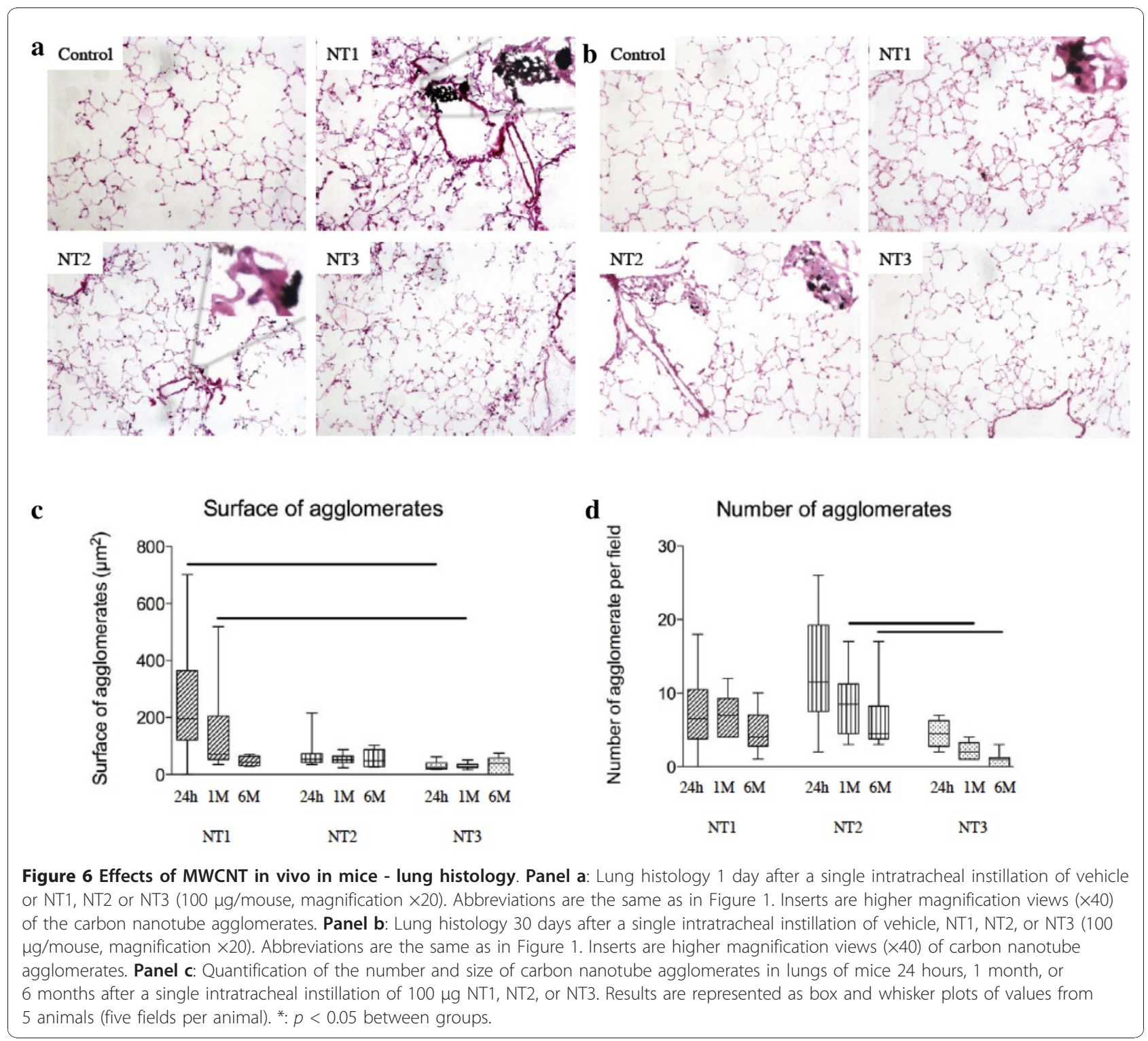

macrophages exposed to MWCNT generated by catalyst chemical vapor deposition was more marked when acidic groups were present on the MWCNT surface, compared to identically produced MWCNT of similar length that did not have acidic groups on their surface (Cyrill Bussy, unpublished data). Moreover, Hamilton and colleagues [36] recently showed that titanium dioxide nanoparticles induced inflammasome activation and inflammatory cytokine release through a cathepsin B-mediated mechanism involving lysosomal disruption and, therefore, acidification of the intracellular compartment, thus linking acidification to inflammatory response. It should be noted, however, that the inflammatory response to NT2, evaluated based on BAL fluid cellularity and lung gene expression, resolved between 1 week and 1 month post-instillation, which probably explained the absence of persistent histological abnormalities. The absence of fibrosis may also reflect the strain of mice used in this study as compared to others [37].

In contrast to the acidic polymer, the polystyrene polymer suppressed the cytotoxicity, oxidative stress, and inflammation observed both in vitro and in vivo when the nanotubes were not coated. Several mechanisms may explain this result. First, the coated MWCNT contained $50 \%$ polymer by weight and therefore contained half the amount of nanotube material supplied by NT1. To investigate the potential role for this difference, we performed in vivo experiments, comparing the effects of $100 \mu \mathrm{g}$ of NT1 to those of a "double dose" of NT2 and NT3 $(200 \mu \mathrm{g}$, thus containing the same amount of MWCNT than $100 \mu \mathrm{g}$ of 


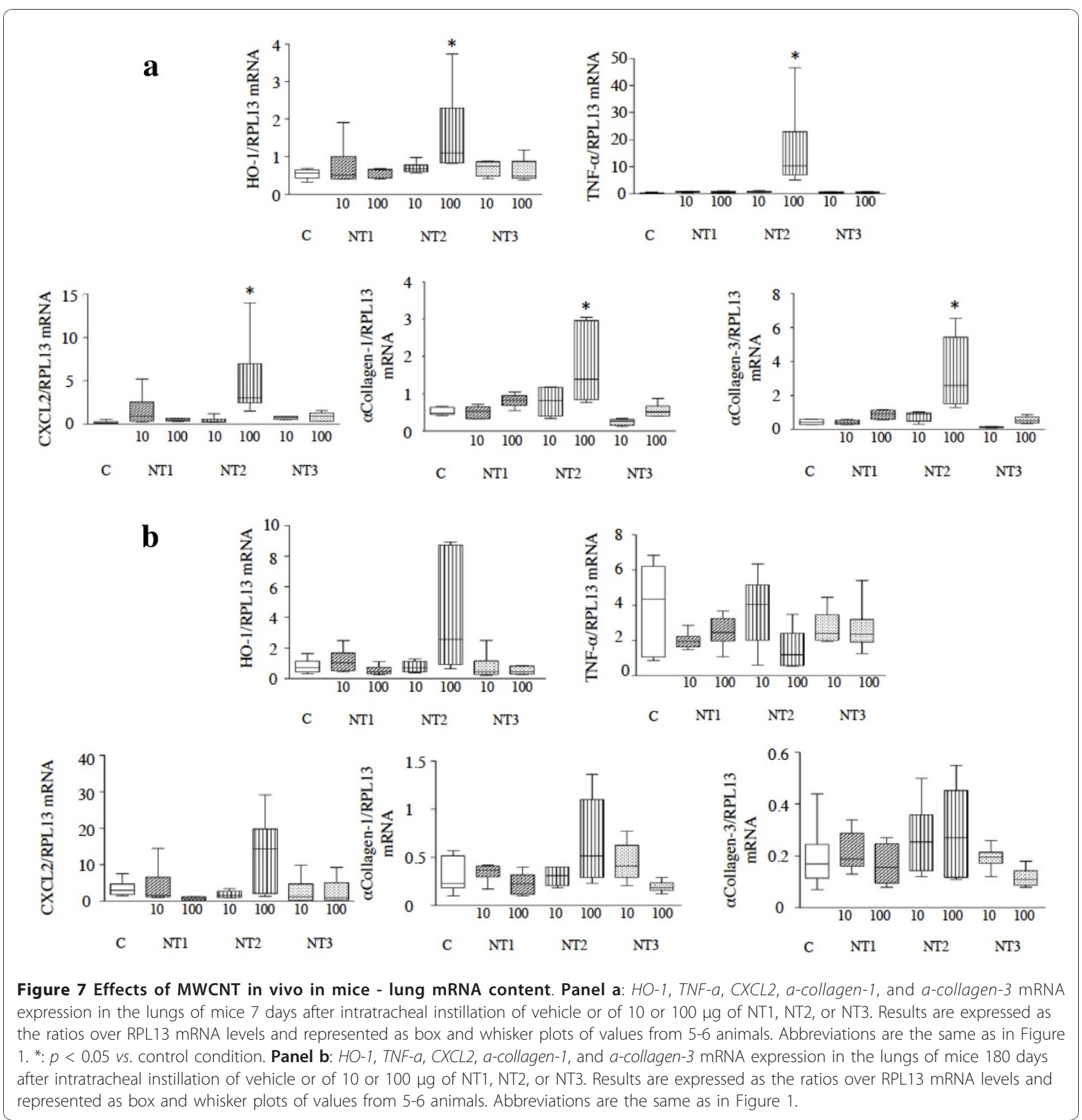

NT1). These experiments showed that BAL fluid cellularity $24 \mathrm{~h}$ after exposure to $200 \mu \mathrm{g}$ NT2 or NT3 was similar to that seen with the original dose of $100 \mu \mathrm{g}$ (data not shown), excluding a role for reduced MWCNT mass in the absence of NT3 toxicity. Second, the specific surface area was smaller with the coated MWCNT than with NT1. However, NT2 and NT3 had similar specific surface areas, yet different toxicities. Third, cell internalization was less marked with NT3 than with the other MWCNT. Similarly, Pan and coworkers [38] showed that coating $\mathrm{TiO}_{2}$ nanoparticles with a dense grafted polymer brush that exhibited hydrophobic properties, also exhibited by our NT3, prevented adherence to the cell membrane and hence penetration into the cell and induction of oxidative stress. Indeed, cells adhere less well to hydrophobic than to hydrophilic biomaterials [39]. However, the reduced internalization of NT3 was probably not the only mechanism explaining the absence of toxicity of this material, since the in vivo experiments showed similar numbers of alveolar macrophages with MWCNT-containing vacuoles in the NT1 and NT3 
groups. Fourth, NT3 may have a decreased ability to induce an oxidative and inflammatory response once internalized, compared to the other two MWCNT. This mechanism is consistent with the presence on the NT3 surface of large numbers of ozone oxidizable groups, compared to the other two MWCNT. These oxidizable groups may act as free radical scavengers [40] thereby decreasing the oxidative stress and consecutive inflammation in NT3-exposed cells and animals. Further studies are needed to determine whether such a mechanism is at play.

We administered MWCNT intratracheally to investigate their effects on the lung. We are aware that inhalation should be preferred over intratracheal instillation for toxicological investigations [41] but we believe our study is relevant to the analysis of the importance of surface characteristics as a determinant of MWCNT toxicity, as we compared the effects of the three materials administered to mice in the same way and using the same experimental set-up. Furthermore, the consistency of the results from our simultaneous in vitro and in vivo investigations supports the validity of our findings.

\section{Conclusions}

In conclusion, to the best of our knowledge, this study supplies the first evidence that using polymer-coating is a useful strategy to diminish adverse effects of CNT. Such tool to modify the surface environment of industrially produced CNT may hold promise for improving occupational safety, as well as general user's safety.

\section{Additional material}

Additional file 1: Representative scanning electron microscopy (SEM) of CNT uncoated (NT1) and coated with carboxylic polyacid or polystyrene polybutadiene polymetacrylate of methyl polymers (NT2 and NT3 respectively).

Additional file 2: Representative transmission electronic microscopy (TEM) images of RAW 264.7 cells exposed for $24 \mathrm{~h}$ to $10 \mu \mathrm{g} / \mathrm{ml}$ of NT1. Panel a: focus is performed on cellular structures. Panel $\mathbf{b}$ : focus is performed on individual CNT inside the cell. Abbreviations are the same as in Figure 1.

Additional file 3: Cell viability assessed by MTT assay. Viability was expressed as a percentage of control cell values, after $6 \mathrm{~h}$ exposure to $100 \mu \mathrm{g} / \mathrm{ml}$ CB, Crocidolite, or 0.1 to $100 \mu \mathrm{g} / \mathrm{ml}$ NT1, NT2 or NT3.

Abbreviations are the same as in Figure 1 and 2. Results are represented as box and whiskers for values obtained in 3-6 experiments. *: $p<0.05$ vs control condition.

Additional file 4: Cell viability assessed by MTT assay. Viability was expressed as a percentage of control cell values, after 24h exposure to Polymers alone (Carb. Pol.: carboxylic polyacid polymer, PMMA Pol.: polystyrene polybutadiene polymethylmethacrylate polymer), or $100 \mu \mathrm{g} /$ $\mathrm{ml} \mathrm{CB}$, Crocidolite, NT1, NT2 or NT3. Abbreviations are the same as in Figure 1 and 2. Results are represented as box and whiskers for values obtained in 3-6 experiments. *: $p<0.05$ vs control condition.

Additional file 5: Effect of NT1, NT2 or NT3 in a dose of 100 or 200 $\mu \mathrm{g} / \mathrm{mouse}$ on total cell content of bronchoalveolar lavage fluid
(BALF) after 1 day exposure. Results are represented as box and whisker plots of values from 4-6 animals per group. Abbreviations are the same as in Additional file 4. *: $p<0.05$ compared to control mice.

Additional file 6: Representative optical microscopy images of cells from BAL after 1 day exposure to CNT vehicle or $100 \mu \mathrm{g} /$ mouse NT1, NT2 or NT3 (magnification $\times 10$ ). Abbreviations are the same as in Figure 1 and 2.

Additional file 7: Lung histology 1 week after a single intratracheal instillation of CNT vehicle or NT1, NT2 or NT3 $(100 \mu \mathrm{g} / \mathrm{mouse}$, magnification $\times 20$ ). Abbreviations are the same as in Figure 1 and 2 . Inserts are higher magnification $(\times 40)$ of $\mathrm{CNT}$ agglomerates.

Additional file 8: Lung histology 3 months after a single intratracheal instillation of CNT vehicle or NT1, NT2 or NT3 $(100 \mu \mathrm{g} /$ mouse, magnification $\times 20$ ). Abbreviations are the same as in Figure 1 and 2. Inserts are higher magnification ( $\times 40)$ of CNT agglomerates.

Additional file 9: Lung histology 6 months after a single intratracheal instillation of CNT vehicle or NT1, NT2 or NT3 $(100 \mu \mathrm{g} /$ mouse, magnification $\times 20$ ). Abbreviations are the same as in Figure 1 and 2. Inserts are higher magnification ( $\times 40)$ of CNT agglomerates.

Additional file 10: Higher magnification ( $\times 40)$ of clusters of cells surrounding visible NT1 (left panel) or NT2 (right panel) agglomerates, 1 month post-instillation.

\section{Acknowledgements}

Lyes Tabet was a recipient of a joint grant from ADEME (Agence de I'Environnement et de la Maitrîse de l'Énergie) and ARKEMA. The authors thank Olivier Thibaudeau (Plate-Forme de Morphologie, Hôpital Bichat) for his assistance in preparing the anatomic specimens and Hélène Desqueyroux (ADEME) for her helpful comments.

\section{Author details}

'INSERM U955, Créteil, F-94010 France, and Université Paris Est Val de Marne (UPEC), Créteil, F-94010, France. ${ }^{2}$ Institut universitaire romand de Santé au Travail (Institute for Work and Health), Université de Lausanne et Université de Genève, Rue du Bugnon 21, CH-1011 Lausanne, Switzerland. 'Laboratory of atmospheric chemistry (LAC), Paul Scherrer Institut (PSI), OFLA008, CH5232 Villigen PSI, Switzerland. ${ }^{4}$ AP-HP, Hôpital Henri Mondor, Service de Physiologie Explorations Fonctionnelles, 94010 Créteil, France. ${ }^{5}$ Hôpital Intercommunal de Créteil, Service de pneumologie et pathologie professionnelle, Créteil, 94000, France. ${ }^{6}$ Department of Environmental Toxicology, University of California, Davis, CA 95616, USA.

\section{Authors' contributions}

$L T, C B, J B$, and $S L$ designed the study. $L T, C B$ and ASD performed the biological assays. AS and MR performed the physicochemical measurements. $J B$ and $S L$ drafted the manuscript, and CB and MR helped with the final version. All authors read and approved the final manuscript.

\section{Competing interests}

The authors declare that they have no competing interests.

Received: 14 September 2010 Accepted: 21 January 2011 Published: 21 January 2011

\section{References}

1. Simeonova PP: Update on carbon nanotube toxicity. Nanomed 2009, 4:373-375.

2. Shvedova AA, Kagan VE, Fadeel B: Close encounters of the small kind: adverse effects of man-made materials interfacing with the nanocosmos of biological systems. Annu Rev Pharmacol Toxicol 2010, 50:63-88.

3. Oberdörster G: Safety assessment for nanotechnology and nanomedicine: concepts of nanotoxicology. Journal of Internal Medicine 2010, 267:89-105.

4. Warheit DB, Sayes CM, Reed KL, Swain KA: Health effects related to nanoparticle exposures: Environmental, health and safety considerations for assessing hazards and risks. Pharmacol Ther 2008, 120:35-42. 
5. Li Z, Hulderman T, Salmen R, Chapman R, Leonard SS, Young SH, Shvedova A, Luster MI, Simeonova PP: Cardiovascular effects of pulmonary exposure to single-wall carbon nanotubes. Environ Health Perspect 2007, 115:377-382.

6. Helland A, Wick P, Koehler A, Schmid K, Som C: Reviewing the environmental and human health knowledge base of carbon nanotubes. Environ Health Perspect 2007, 115:1125-1131.

7. Nemmar A, Hoylaerts MF, Hoet PH, Dinsdale D, Smith T, Xu H, Vermylen J, Nemery B: Ultrafine particles affect experimental thrombosis in an in vivo hamster model. Am J Respir Crit Care Med 2002, 166:998-1004.

8. Nemmar A, Vanbilloen H, Hoylaerts MF, Hoet PH, Verbruggen A, Nemery B: Passage of intratracheally instilled ultrafine particles from the lung into the systemic circulation in hamster. Am J Respir Crit Care Med 2001, 164:1665-1668.

9. Brown J, Zeman K, Bennett W: Ultrafine particle deposition and clearance in the healthy and obstructed lung. Am J Respir Crit Care Med 2002, 166:1240-1247.

10. Nel A, Xia T, Madler L, Li N: Toxic potential of materials at the nanolevel. Science 2006, 311:622-627.

11. Poland CA, Duffin R, Kinloch I, Maynard A, Wallace WA, Seaton A, Stone V, Brown S, Macnee W, Donaldson K: Carbon nanotubes introduced into the abdominal cavity of mice show asbestos-like pathogenicity in a pilot study. Nat Nanotechnol 2008, 3:423-428.

12. Lam CW, James JT, McCluskey R, Arepalli S, Hunter RL: A review of carbon nanotube toxicity and assessment of potential occupational and environmental health risks. Crit Rev Toxicol 2006, 36:189-217.

13. Stern ST, McNeil SE: Nanotechnology safety concerns revisited. Toxicol Sci 2008, 101:4-21

14. Sydlik U, Gallitz I, Albrecht C, Abel J, Krutmann J, Unfried K: The compatible solute ectoine protects against nanoparticle-induced neutrophilic lung inflammation. Am J Respir Crit Care Med 2009, 180:29-35.

15. Fenoglio I, Greco G, Tomatis M, Muller J, Raymundo-Pinero E, Beguin F, Fonseca A, Nagy JB, Lison D, Fubini B: Structural defects play a major role in the acute lung toxicity of multiwall carbon nanotubes: physicochemical aspects. Chem Res Toxicol 2008, 21:1690-1697.

16. Johnston HJ, Hutchison GR, Christensen FM, Peters S, Hankin S, Aschberger K, Stone $V$ : A critical review of the biological mechanisms underlying the in vivo and in vitro toxicity of carbon nanotubes: The contribution of physico-chemical characteristics. Nanotoxicology 2010, 4:207-246.

17. Kayat J, Gajbhiye V, Tekade RK, Jain NK: Pulmonary toxicity of carbon nanotubes: a systematic report. Nanomedicine 2010, xx:1-10.

18. Tong H, McGee JK, Saxena RK, Kodavanti UP, Devlin RB, Gilmour MI: Influence of acid functionalization on the cardiopulmonary toxicity of carbon nanotubes and carbon black particles in mice. Toxicol Appl Pharmacol 2009, 239:224-232.

19. Vittorio O, Raffa V, Cuschieri A: Influence of purity and surface oxidation on cytotoxicity of multi-wall carbon nanotubes with human neuroblastoma cells. Nanomedicine 2009, 5:424-431.

20. Ciobanu M, Siove A, Gueguen V, Gamble L, Castner DG, Migonney V: Radical graft polymerization of styrene sulfonate on poly(ethylene terephthalate) films for ACL applications: "grafting from" and chemical characterization. Biomacromolecules 2006, 7:755-760.

21. Rossi MJ, Demirdjian B: The surface properties of SOA generated from limonene and toluene using specific molecular probes: exploration of a new experimental technique. Atmos Chem Phys Discuss 2005, 5:1-48.

22. Setyan A, Sauvain JJ, Rossi MJ: The use of heterogeneous chemistry for the characterization of functional groups at the gas/particle interface of soot and TiO2 nanoparticles. Phys Chem Chem Phys 2009, 11:6205-6217.

23. Tabet L, Bussy C, Amara N, Setyan A, Grodet A, Rossi MJ, Pairon JC, Boczkowski J, Lanone S: Adverse effects of industrial multiwalled carbon nanotubes on human pulmonary cells. J Toxicol Environ Health A 2009, 72:60-73.

24. Bussy C, Cambedouzou J, Lanone S, Leccia E, Heresanu V, Pinault M, Mayne-L'hermite M, Brun N, Mory C, Cotte M, et al: Carbon Nanotubes in Macrophages: Imaging and Chemical Analysis by X-ray Fluorescence Microscopy. Nano Lett 2008, 8:2659-2663.

25. Herzog E, Byrne HJ, Davoren M, Casey A, Duschl A, Oostingh GJ: Dispersion medium modulates oxidative stress response of human lung epithelial cells upon exposure to carbon nanomaterial samples. Toxicol Appl Pharmacol 2009, 236:276-281.
26. Worle-Knirsch JM, Pulskamp K, Krug HF: Oops they did it again! Carbon nanotubes hoax scientists in viability assays. Nano Lett 2006, 6:1261-1268.

27. Oberdörster G, Yu CP: Lung dosimetry - Considerations for noninhalation studies. Exp Lung Res 1999, 25:1-6.

28. Bachoual R, Boczkowski J, Goven D, Amara N, Tabet L, On D, Lecon-Malas V, Aubier M, Lanone S: Biological effects of particles from the paris subway system. Chem Res Toxicol 2007, 20:1426-1433.

29. Plantier L, Marchand-Adam S, Antico VG, Boyer L, De Coster C, Marchal J, Bachoual R, Mailleux A, Boczkowski J, Crestani B: Keratinocyte growth factor protects against elastase-induced pulmonary emphysema in mice. Am J Physiol Lung Cell Mol Physiol 2007, 293:L1230-1239.

30. Davoren M, Herzog E, Casey A, Cottineau B, Chambers G, Byrne HJ, Lyng FM: In vitro toxicity evaluation of single walled carbon nanotubes on human A549 lung cells. Toxicol In Vitro 2007, 21:438-448.

31. Muller J, Huaux F, Moreau N, Misson P, Heilier JF, Delos M, Arras M, Fonseca A, Nagy JB, Lison D: Respiratory toxicity of multi-wall carbon nanotubes. Toxicol Appl Pharmacol 2005, 207:221-231.

32. Wick $P$, Manser $P$, Limbach LK, Dettlaff-Weglikowska U, Krumeich F, Roth $S$, Stark WJ, Bruinink A: The degree and kind of agglomeration affect carbon nanotube cytotoxicity. Toxicol Lett 2007, 168:121-131.

33. Czajkowska B, Blazewicz M: Phagocytosis of chemically modified carbon materials. Biomaterials 1997, 18:69-74.

34. Hussain S, Boland S, Baeza-Squiban A, Hamel R, Thomassen LC, Martens JA, Billon-Galland MA, Fleury-Feith J, Moisan F, Pairon JC, Marano F: Oxidative stress and proinflammatory effects of carbon black and titanium dioxide nanoparticles: role of particle surface area and internalized amount. Toxicology 2009, 260:142-149.

35. Shvedova AA, Kisin ER, Murray AR, Johnson VJ, Gorelik O, Arepalli S, Hubbs AF, Mercer RR, Keohavong P, Sussman N, et al: Inhalation Versus Aspiration of Single Walled Carbon Nanotubes in C57bl/6 Mice: Inflammation, Fibrosis, Oxidative Stress and Mutagenesis. Am J Physiol Lung Cell Mol Physiol 2008, 95:L552-565.

36. Hamilton RF Jr, Wu N, Porter D, Buford M, Wolfarth M, Holian A: Particle length-dependent titanium dioxide nanomaterials' toxicity and bioactivity. Part Fibre Toxicol 2009, 6:35.

37. Crouzier D, Follot S, Gentilhomme E, Flahaut E, Arnaud R, Dabouis V Castellarin C, Debouzy JC: Carbon nanotubes induce inflammation but decrease the production of reactive oxygen species in lung. Toxicology 272:39-45

38. Pan Z, Lee W, Slutsky L, Clark RA, Pernodet N, Rafailovich MH: Adverse Effects of Titanium Dioxide Nanoparticles on Human Dermal Fibroblasts and How to Protect Cells. Small 2009, 5:511-520.

39. Arima $Y$, Iwata $H$ : Effect of wettability and surface functional groups on protein adsorption and cell adhesion using well-defined mixed selfassembled monolayers. Biomaterials 2007, 28:3074-3082.

40. Fenoglio I, Tomatis M, Lison D, Muller J, Fonseca A, Nagy JB, Fubini B: Reactivity of carbon nanotubes: free radical generation or scavenging activity? Free Radic Biol Med 2006, 40:1227-1233.

41. Donaldson K, Poland CA: Nanotoxicology: new insights into nanotubes. Nat Nanotechnol 2009, 4:708-710.

doi:10.1186/1743-8977-8-3

Cite this article as: Tabet et al: Coating carbon nanotubes with a polystyrene-based polymer protects against pulmonary toxicity. Particle and Fibre Toxicology 2011 8:3.

\section{Submit your next manuscript to BioMed Central and take full advantage of:}

- Convenient online submission

- Thorough peer review

- No space constraints or color figure charges

- Immediate publication on acceptance

- Inclusion in PubMed, CAS, Scopus and Google Scholar

- Research which is freely available for redistribution 